\title{
Tuning Parameters of Fuzzy Logic Controller using PSO for Maglev System
}

\author{
Huynh Nhu Truong \\ BCTECH \\ Thanh Tan, Dat Do, BR-VT
}

\author{
Xuan Khoat Ngo \\ $\mathrm{BCTECH}$ \\ Thanh Tan, Dat Do, BR-VT
}

\begin{abstract}
The paper proposes to use Particle Swarm Optimization (PSO) to tune parameters of a fuzzy logic controller for regulating a magnetic levitation (maglev) system at a desired position. PSO is a meta-heuristic search method. This method is inspired by bird flocking behavior searching for food. In this study, the rule base of the Fuzzy Logic Controller (FLC) is brought by expert experience, and the parameters of the controller including the membership function parameters and scaling gains will be optimally tuned by the PSO such that a quadratic criterion is minimized. Simulation results show that the designed fuzzy controller is able to stabilize the position of the maglev system. Besides, a state feedback controller is also used to regulate the maglev system. Although, the simulation results show that FLC gives performance better than the state feedback controller but the latter is more robust.
\end{abstract}

\section{General Terms}

Algorithms.

\section{Keywords}

Fuzzy Logic Controller, PSO, Maglev.

\section{INTRODUCTION}

Magnetic levitation systems have been used in many engineering systems such as high-speed maglev passenger trains, frictionless bearings, levitation of wind tunnel models, vibration isolation of sensitive machinery, levitation of molten metal in induction furnaces, and levitation of metal slabs during manufacturing [1]. Due to highly nonlinear, open-loop instability and fast response, they become a benchmark model for validating controllers. In recent years, a large number of works have been reported in literature for controlling maglev system. In [1], authors used PID controller whose controller gains are determined via Linear Quadratic Regulator (LQR) approach to stabilize the ball position of maglev system. Experiments are conducted on a Quanser magnetic levitation system to evaluate the performance of the proposed methodology and the experimental results prove that the proposed control strategy is effective not only in stabilizing the ball but also in rejecting the disturbance present in the system. Another method was used to design PID controller for stabilizing maglev system is IMC [2]. In [3], a self-tuning robust integral of signum of error (RISE) based controller is designed and used to control a maglev system. The controller is tested on an experimental maglev system and successful results are obtained. Authors in [4] based on state-dependent ARX model to design a predictive controller to stabilize the magnetic levitation ball to a given position or to make it track a desired trajectory. The real-time control results of the proposed approach and the comparisons with other two approaches are given, which demonstrate that the modeling and control method presented in this paper are very effective and superior in controlling the fast-responding, strongly nonlinear and open-loop unstable system.
In this paper, the author presents an application of the PSO in tuning parameters of a fuzzy logic controller (FLC) for stabilizing the ball position of the maglev system. FLC have been successfully applied to control many objects that are high nonlinear or open-loop unstable but finding parameters such as scaling gains and membership function is difficult. Normally, they are identified by trial and error method. Recently, some optimal methods have been used to find these parameters. In [5], authors used PSO algorithm to determine Fuzzy control rules in order to avoids falling in local optimum by setting variable inertia weight and learning factors. Simulation results show that the proposed approach achieves better dynamic performance compared with conventional proportional and integral (PI) controller in four-area reheat thermal and hydro AGC system. In [6] and [7], authors used PSO to optimize FLC for speed control of Quasi-Z Source DC/DC converter fed drive and Self-Balancing Two-Wheeled Robot. Results show that effectiveness of PSO-based fuzzy control. In [6], the proposed method has been tested and examined for two types of DC/DC converters fed DC drive. The results of fuzzy PSO were compared with that of conventional fuzzy and genetic algorithm based fuzzy controller. The fuzzy PSO based controller was found to be more viable as it gave minimum rise time, settling time, steady state error and also ripples in the armature current was found to be minimized. In [7], the proposed novel LMI-based PSO algorithm not only stabilizes the self-balance control system of two-wheeled robot but also seeks the best control gains.

The remains of this paper are organized as follows. Section 2 introduces the model of the maglev system. Section 3 presents overview and algorithm of the PSO. The description how to design and tune parameters of the fuzzy controller is given in section 4. Section 5 shows obtained results and Section 6 concludes this paper.

\section{MODEL OF THE MAGLEV SYSTEM}

Model of the maglev system is shown in Fig 1, where $V_{c}$ is the control input and $I_{c}$ is electric current to the coil, $R_{c}$ and $L_{c}$ is its resistance and inductance respectively, $R_{s}$ is shunt resistance to feedback current, $M_{b}$ is the ball mass. The details of the parameters and values are given is Table 1. Referring [8] for more information. 


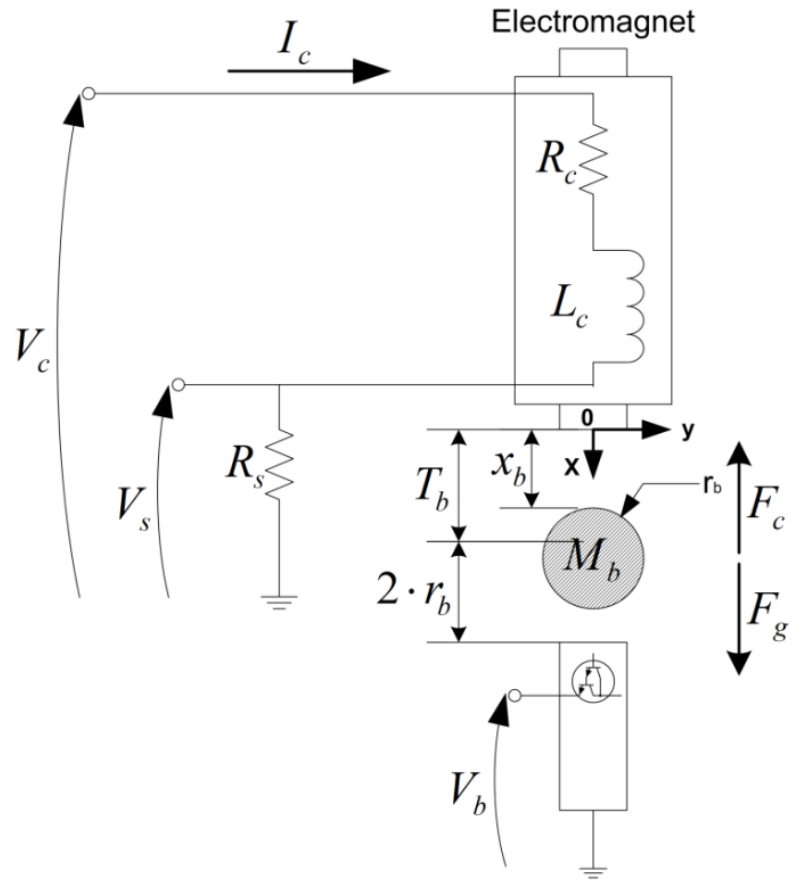

Fig 1: Schematic of the Maglev system

Table 1. Maglev system parameters

\begin{tabular}{|c|c|c|c|}
\hline Symbol & Description & Value & Unit \\
\hline$L_{c}$ & Coil inductance & 412.5 & $\mathrm{mH}$ \\
\hline$R_{c}$ & Coil resistance & 10 & $\Omega$ \\
\hline$R_{s}$ & Shunt resistance & 1 & $\Omega$ \\
\hline$K_{m}$ & $\begin{array}{c}\text { Electromagnet force } \\
\text { constant }\end{array}$ & $\begin{array}{c}6.5308 \mathrm{e}- \\
5\end{array}$ & $\mathrm{~N} . \mathrm{m}^{2} / \mathrm{A}^{2}$ \\
\hline$M_{b}$ & Ball mass & 0.068 & $\mathrm{Kg}$ \\
\hline$r_{b}$ & Ball radius & $1.27 \mathrm{e}-2$ & $\mathrm{~m}$ \\
\hline
\end{tabular}

By applying Kirchhoff's voltage law, it can be obtained the electric equation as:

$$
V_{c}(t)=\left(R_{c}+R_{s}\right) I_{c}(t)+L_{c}\left(\frac{d}{d t} I_{c}(t)\right)
$$

The gravitational force applied on the ball:

$$
F_{g}=M_{b} g
$$

The electromagnetic force applied on the ball:

$$
F_{c}(t)=\frac{1}{2} \frac{K_{m} I_{c}^{2}(t)}{x_{b}^{2}(t)}
$$

The total force applied on the ball:

$$
F_{g}+F_{c}(t)=M_{b} g-\frac{1}{2} \frac{K_{m} I_{c}^{2}(t)}{x_{b}^{2}(t)}
$$

Applying the Newton's second law, the equation of motion can be obtained as:

$$
\frac{d^{2}}{d t^{2}} x_{b}(t)=g-\frac{1}{2} \frac{K_{m} I_{c}^{2}(t)}{M_{b} x_{b}^{2}(t)}
$$

Equation (5) shows that the maglev system is a nonlinear, unstable system.

\section{PARTICLE SWARM OPTIMIZATION}

\subsection{Overview}

PSO is a global optimization technique that has been developed by Eberhart and Kennedy in 1995 [9]. PSO is a population-based search algorithm where each individual is referred to as particle and represents a candidate solution. In PSO, each particle strives to improve itself by imitating traits from their successful peers. Further, each particle has a memory and hence it is capable of remembering the best position in the search space ever visited by it.

PSO has gained prominence in the last two decades due to its ease of application in unsupervised, complex multidimensional problems which cannot be solved using traditional deterministic algorithms [10].

\subsection{Algorithm}

PSO is initialized by a group of the random particles (solutions), then finding the optimal solution by updating particles through generations. In a generation, each particle will be updated according to two the best particles. The first is the best present particle, called $X_{p}$. The last is the best global particle, called $X_{g}$. The particle updates its position as Fig 2 .

Velocity and position of individual particles updated as follows:

$$
\begin{gathered}
V_{i}^{k+1}=\omega V_{i}^{k}+c_{1} \operatorname{rand}_{1}\left(X_{p i}-X_{i}^{k}\right)+c_{2} \operatorname{rand}_{2}\left(X_{g}-X_{i}^{k}\right) \\
X_{i}^{k+1}=X_{i}^{k}+V_{i}^{k+1}
\end{gathered}
$$

Where:

$V_{i}^{k+1} \quad$ : velocity of particle $\mathrm{i}$ at loop $\mathrm{k}+1$

$$
\begin{array}{ll}
X_{i}^{k+1} & : \text { position of particle } \mathrm{i} \text { at loop } \mathrm{k}+1 . \\
\omega & : \text { inertia weight. } \\
c_{1}, c_{2} & : \text { cognitive and social parameters. }
\end{array}
$$

rand $_{1}$, rand $_{2}$ : random numbers between 0 and 1 .

$X_{p i}$ : best "remembered" individual particle $i$ position.

$X_{g}$ : best "remembered" swarm position.

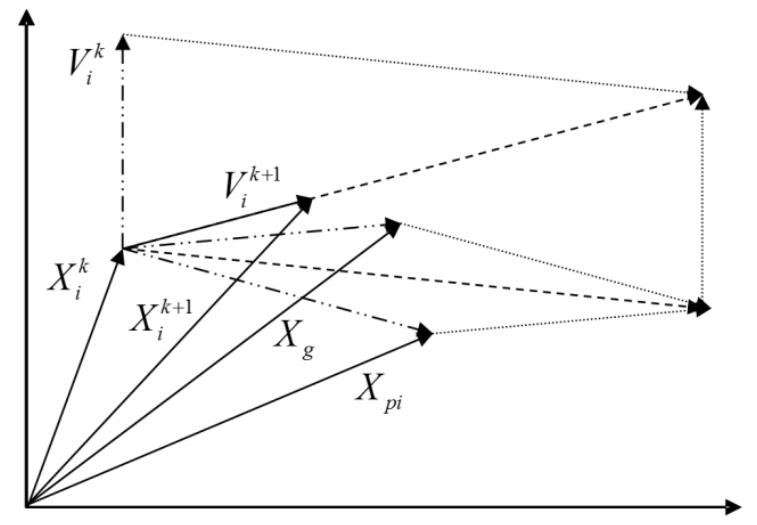

Fig 2: Velocity and position update of a new particle

Flowchart of the PSO as in Fig 3. At beginning, initializing population $N$, inertia weight $\omega$, cognitive and social parameters $c_{1}, c_{2}$. Then, randomly generating the agents of the population and computing the fitness of these agents. Selecting $X_{p}$ and $X_{g}$ based on their fitness. Update the velocity and position of the agents (particles) according to equations 
(6) and (7). This process continues until the convergent criterion is satisfied.

Ability to find the optimal solution of the PSO is influenced by many parameters such as the inertia weight, cognitive and social parameters, the population size, and so on. Selecting of these parameters in this paper based on trial and error, results as Table 2. Selected convergent criterion is the number of the generations, here is 50 .

Table 2. PSO parameters

\begin{tabular}{|c|c|c|c|c|}
\hline Parameters & $\mathbf{N}$ & $\mathbf{c}_{\mathbf{1}}$ & $\mathbf{c}_{\mathbf{2}}$ & $\boldsymbol{\omega}$ \\
\hline Values & 50 & 2.5 & 2.0 & 0.5 \\
\hline
\end{tabular}

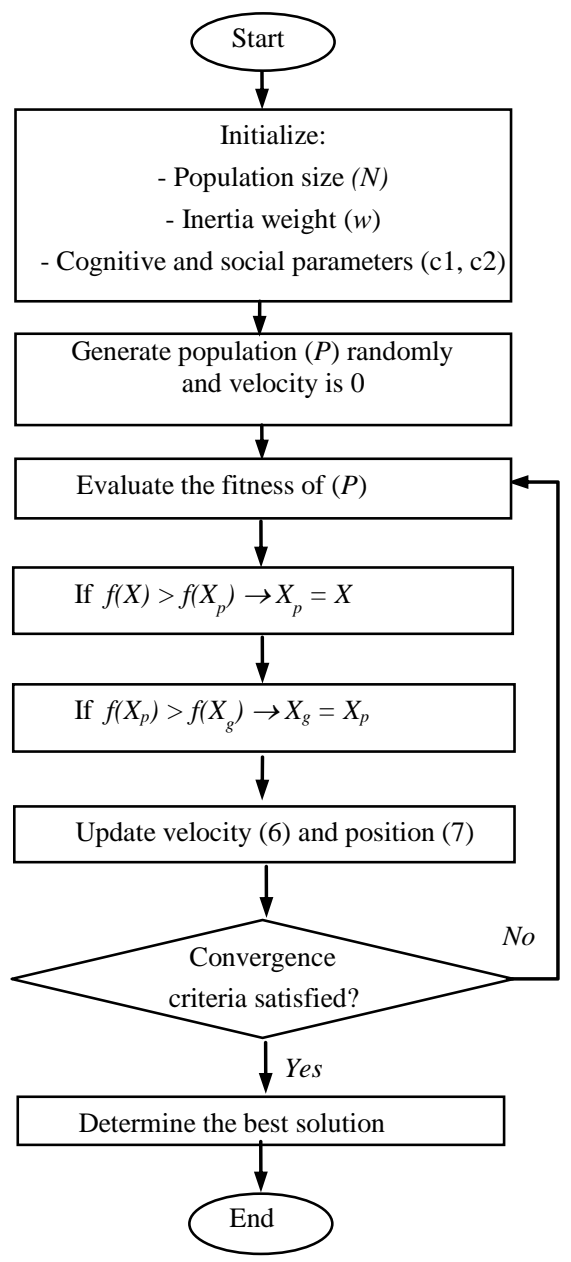

Fig 3: Flowchart of the PSO

\subsection{Subsequent Pages}

\section{DESIGN OF THE FUZZY LOGIC} CONTROLLER FOR MAGLEV SYSTEM

This section discusses the design of a fuzzy logic controller for stabilizing the position of the ball for maglev system presented in section 2. The block diagram of the control system is shown in Fig 4 and configuration of the fuzzy controller as in Fig 5.

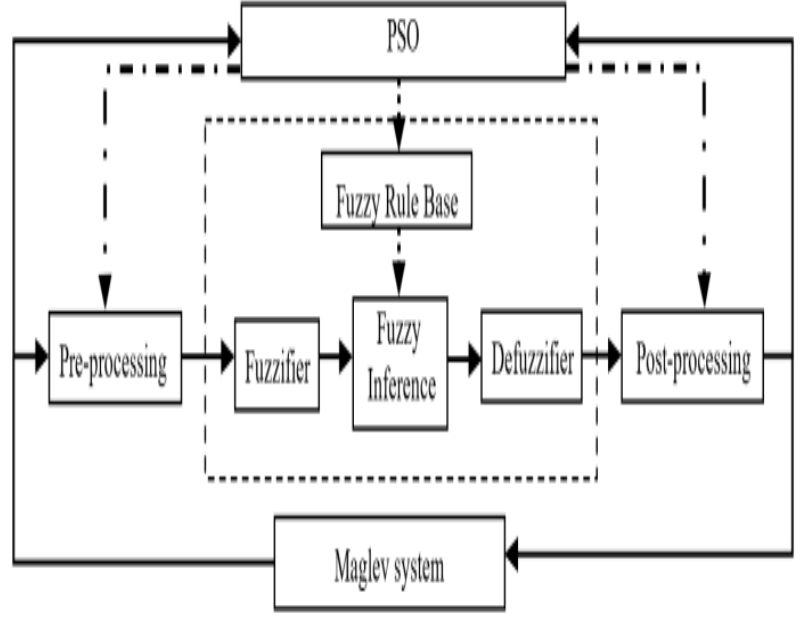

Fig 4: Block diagram of the control system

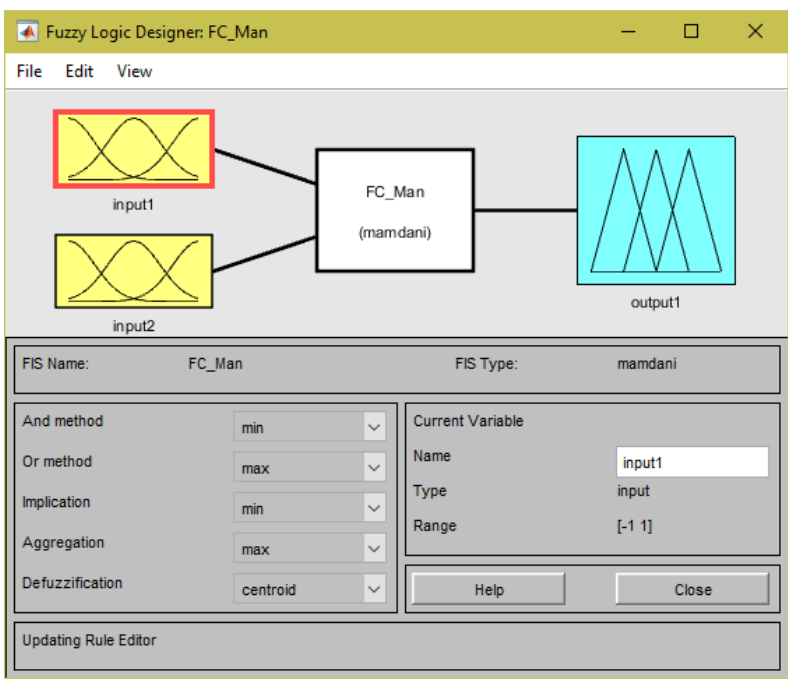

Fig 5: Configuration of the fuzzy controller

Defining 5 linguistic values denoted as NB (Negative Big), NM (Negative Medium), NS (Negative Small), Z (Zero), PS (Positive Small), PM (Positive Medium) và PB (Positive Big) for input and output variables. The linguistic values are qualified by piece-wise membership functions defined in the universe of discourse of $[-1,1]$ as shown in Fig 6,7,8.

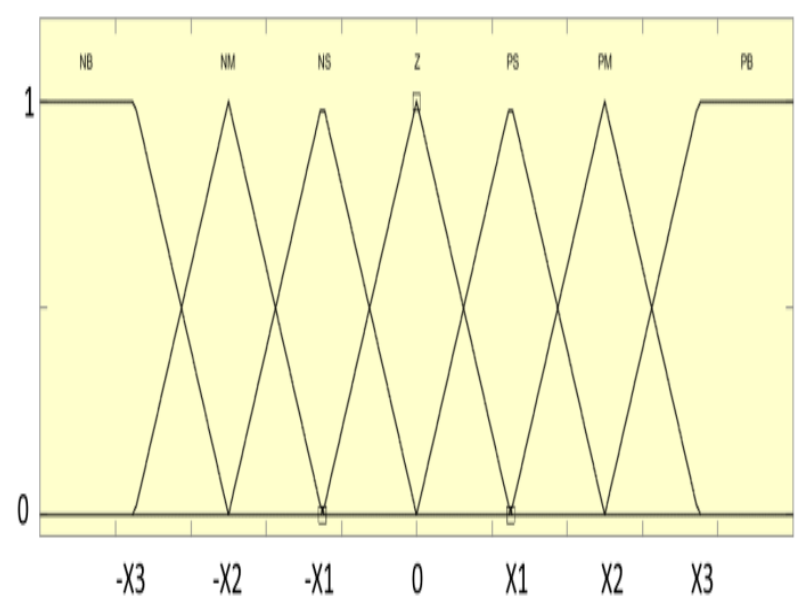

Fig 6: Membership function of error 


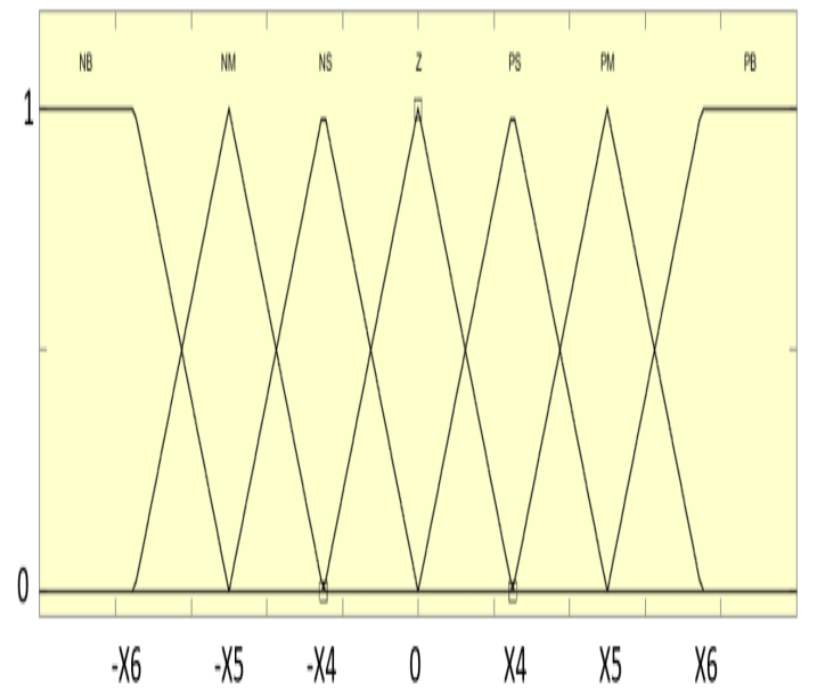

Fig 7: Membership function of differential error

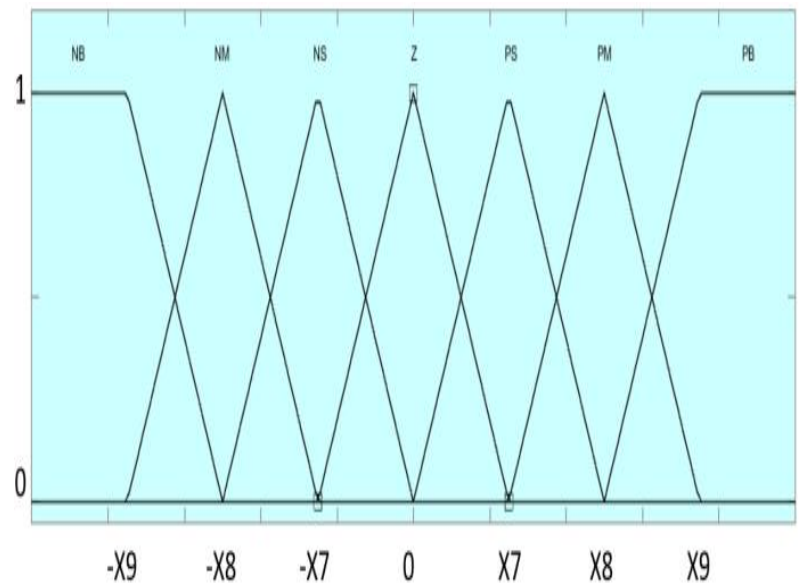

Fig 8: Membership function of control signal

The rule base system consists of 49 (IF...THEN) rules derived from human knowledge. The complete rule base presented in Table 3.

Table 3. Rule base system

\begin{tabular}{|c|c|c|c|c|c|c|c|}
\hline $\begin{array}{c}\text { de } \\
\text { de }\end{array}$ & NB & NM & NS & $\mathbf{Z}$ & PS & PM & PB \\
\hline NB & NB & NB & NB & NB & NM & NS & Z \\
\hline NM & NB & NB & NB & NM & NS & Z & PS \\
\hline NS & NB & NB & NM & NS & Z & PS & PM \\
\hline$Z$ & NB & NM & NS & Z & PS & PM & PB \\
\hline PS & NM & NS & Z & PS & PM & PB & PB \\
\hline PM & NS & Z & PS & PM & PB & PB & PB \\
\hline PB & Z & PS & PM & PB & PB & PB & PB \\
\hline
\end{tabular}

\section{SIMULATION RESULTS}

Matlab and Simulink are used to implement the PSO-based fuzzy logic controller. Simulink model of the control system as Fig 9.

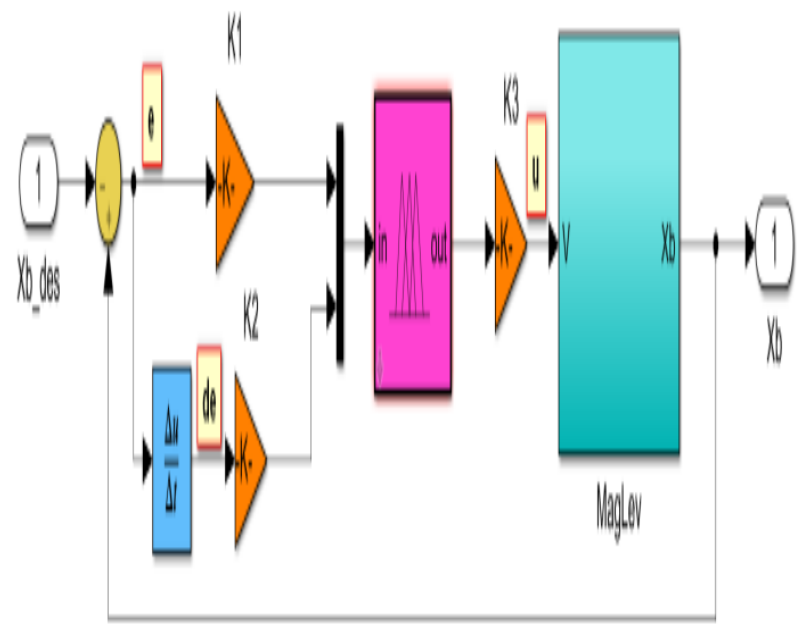

Fig 9: Simulink model of the control system

\subsection{Parameter settings}

The parameters of FLC that need to be tuned consist of 3 scaling gains $\mathrm{K} 1, \mathrm{~K} 2, \mathrm{~K} 3$ and 9 membership function parameters from $\mathrm{X} 1$ to $\mathrm{X} 9$. The weighting matrices in (8) reflecting the desired control performance are chosen to be $\mathrm{Q}=\operatorname{diag}[1000,50]$ and $\mathrm{R}=0.0001$ through a "trial and error" process.

\subsection{Tuning the parameters of the FLC using PSO}

As presented above, 12 parameters of the FLC need to be tuned. The procedures as following:

- $\quad$ Step 1: generating random variables $K_{i}$ and $x_{j}$ with $i=1: 3, j=1: 9$

- Step 2: collecting data error $e$, differential error $d e$ and controlled signal $u$

- Step 3: computing the objective function

$J=e^{T} Q_{11} e+d e^{T} Q_{22} d e+u^{T} R u$

- $\quad$ Step 4: running PSO such that minimizing $J$

- Step 5: repeating steps 2, 3 and 4 until the convergent criterion is satisfied.

\subsection{Results and remarks}

\subsubsection{Results}

The parameters of the FLC are tuned by PSO as presented in table 1 . The responses of the position of the ball and the controlled signal when regulating the maglev at position $5 \mathrm{~mm}$ as shown in Fig 10,11. 
Table 2. The tuned parameters of the FLC

\begin{tabular}{|c|c|c|c|}
\hline Parameters & K1 & K2 & K3 \\
\hline Value & 96.8278 & 2.6142 & 27.9964 \\
\hline Parameters & $\mathbf{X 1}$ & $\mathbf{X 2}$ & $\mathbf{X 3}$ \\
\hline Value & 0.0010 & 0.3422 & 0.7211 \\
\hline Parameters & $\mathbf{X 4}$ & $\mathbf{X 5}$ & $\mathbf{X 6}$ \\
\hline Value & 0.0485 & 0.6164 & 0.7300 \\
\hline Parameters & $\mathbf{X 7}$ & $\mathbf{X 8}$ & $\mathbf{X 9}$ \\
\hline Value & 0.2041 & 0.6365 & 0.9990 \\
\hline
\end{tabular}

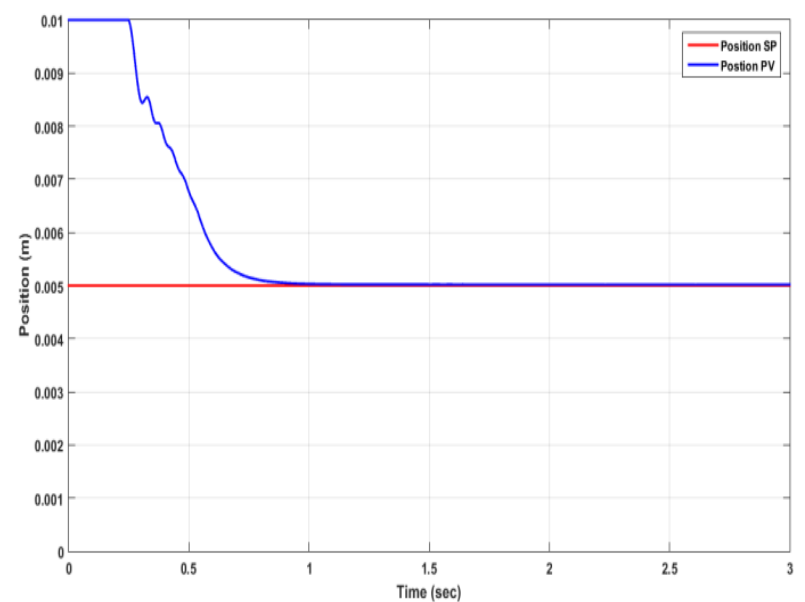

Fig 10: Response of the ball position

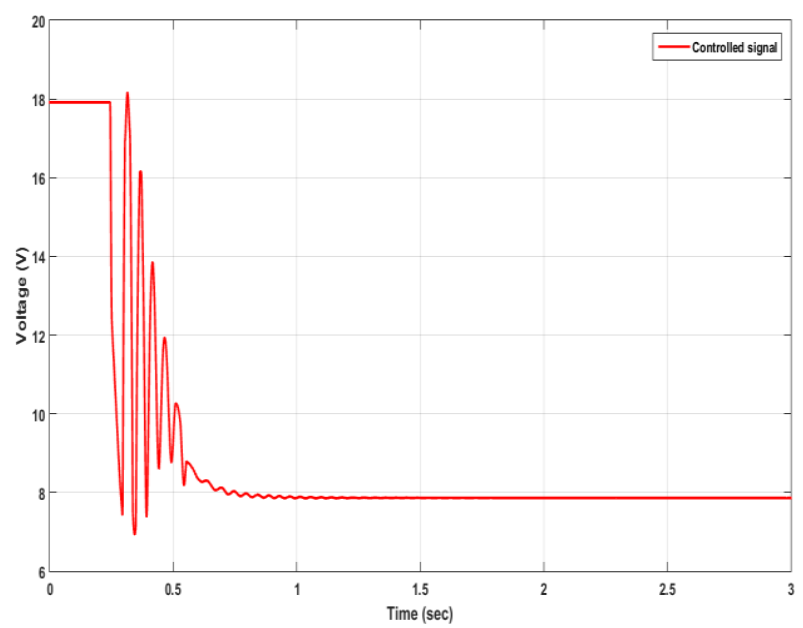

Fig 11: Response of the controlled signal

In order to compare to the FLC, a state feedback controller is used. This controller is designed by pole placement method. The response of the state feedback controller is as Fig 12,13. When changing the desired position into $3 \mathrm{~mm}$, FLC can't stabilize the ball position while the state feedback controller can do.

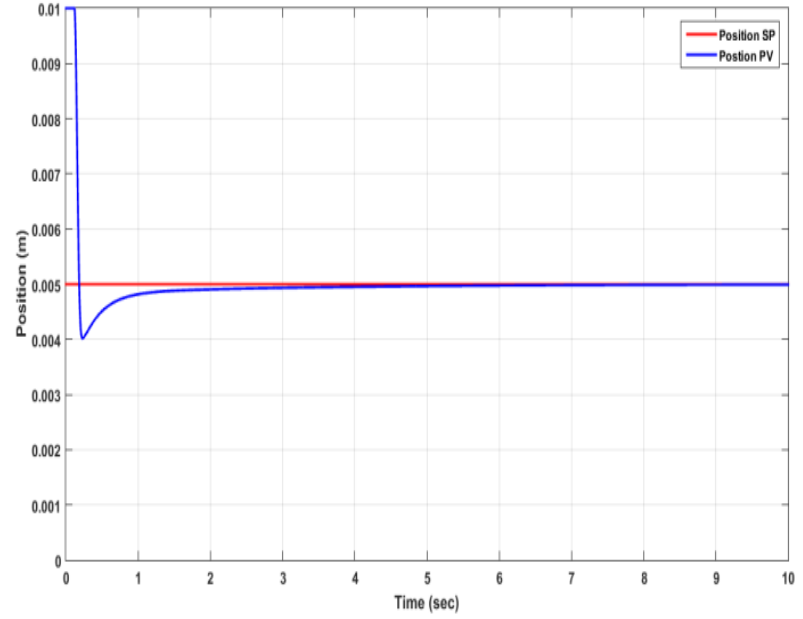

Fig 12: Response of the ball position

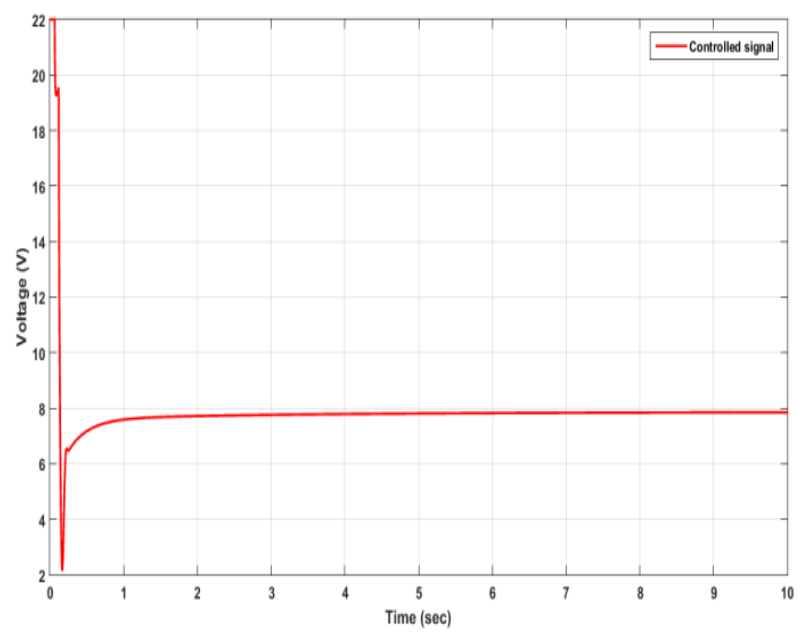

Fig 13: Response of the controlled signal

\subsubsection{Remarks}

From above simulation results, it can be seen that both the FLC and the state feedback controller can stabilize the ball at a desired position. The FLC gives performance better than state feedback controller: no overshoot, shorter settling time.

However, as changing desired position, the FLC can't stabilize the ball while state feedback controller can do. That can be explained is due to the FLC only feedback position of the ball (one state) and the parameters of the FLC is tuned at a given position while state feedback controller feedback all states (position, velocity and current).

\section{CONCLUSION}

In this paper, PSO method is used to tune the parameters of the FLC, including 3 scaling gains and 9 membership functions. The simulation results show that the designed FLC can stabilize the ball position of the maglev system. Furthermore, the designed FLC gives control performance better than the state feedback controller. However, the FLC is not robust. When changing setpoint, FLC can't stabilize the ball position. So, in future, the configuration of the FLC needs to be modified for the maglev system. The designed FLC is also applied on real maglev system to validate further its performance. 


\section{REFERENCES}

[1] Vinodh Kumar E, Jovitha Jerome. 2013. LQR based optimal tuning of PID controller for trajectory tracking of Magnetic Levitation System. IConDM. Elsevier Ltd.

[2] Adrian-Vasile Duka, Mircea Dulău, Stelian-Emilian Oltean. 2016. IMC Based PID Control of a Magnetic Levitation System. Procedia Technology. Elsevier Ltd.

[3] Baris Bidikli, Alper Bayrak. 2018. A self-tuning robust full-state feedback control design for the magnetic levitation system. Control Engineering Practice. Elsevier Ltd.

[4] Yemei Qin, et al. 2013. A modeling and control approach to magnetic levitation system based on state-dependent ARX model. Journal of Process Control. Elsevier Ltd.

[5] H. Guolian, Q. Lina, Z. Xinyan et al. 2012. Application of PSO-based fuzzy PI controller in multi-area AGC system after deregulation. 7th IEEE Int. Conf. on Industrial Electronics and Applications (ICIEA).

[6] M. Ranjani, M. Ranjani. 2015. Optimal fuzzy controller parameters using PSO for speed control of Quasi-Z
Source DC/DC converter fed drive. Journal Applied Soft Computing.

[7] Gwo-Ruey Yu,Yuan-Kai Leu, H.-T. Huang. 2017. PSObased Fuzzy Control of a Self-Balancing Two-Wheeled Robot. IFSA-SCIS. IEEE.

[8] Quanser. 2012. Magnetic Levitation Experiment for MATLAB /Simulink Users.

[9] J. Kennedy and R. C. 1995. Eberhart. Particle swarm optimization. Proceedings of IEEE International Conference on Neural Networks (Perth, Australia), IEEE Service Center, Piscataway.

[10] Saptarshi Sengupta, Sanchita Basak and Richard Alan Peters II. 2019. Particle Swarm Optimization: A survey of historical and recent developments with hybridization perspectives. arXiv:1804.05319v2 [cs.NE].

[11] Duc-Hoang Nguyen. 2015. A Hybrid SFL-Bees Algorithm. International Journal of Computer Applications. Published by Foundation of Computer Science (FCS), NY, USA. 